\title{
Recovery of new-onset kidney disease in COVID-19 patients discharged from hospital
}

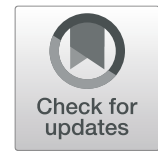

\author{
Nan-Hui Zhang ${ }^{\dagger}$, Yi-Chun Cheng ${ }^{\dagger}$, Ran Luo, Chun-Xiu Zhang, Shu-Wang Ge ${ }^{*}$ and Gang Xu
}

\begin{abstract}
Background: Coronavirus disease 2019 (COVID-19) has emerged as a major global health threat with a great number of deaths worldwide. Despite abundant data on that many COVID-19 patients also displayed kidney disease, there is limited information available about the recovery of kidney disease after discharge.

Methods: Retrospective and prospective cohort study to patients with new-onset kidney disease during the COVID19 hospitalization, admitted between January 28 to February 26, 2020. The median follow-up was 4 months after discharge. The follow-up patients were divided into the recovery group and non-recovery group. Descriptive statistics and between-groups comparison were used.

Results: In total, 143 discharged patients with new-onset kidney disease during the COVID-19 hospitalization were included. Patients had a median age was 64 (IQR, 51-70) years, and 59.4\% of patients were men. During 4-months median follow-up, 91\% (130 of 143) patients recovered from kidney disease, and 9\% (13 of 143) patients haven't recovered. The median age of patients in the non-recovery group was 72 years, which was significantly higher than the median age of 62 years in the recovery group. Discharge serum creatinine was significantly higher in the nonrecovery group than in the recovery group.

Conclusions: Most of the new-onset kidney diseases during hospitalization of COVID-19 patients recovered 4 months after discharge. We recommend that COVID-19 patients with new-onset kidney disease be followed after discharge to assess kidney recovery, especially elderly patients or patients with high discharge creatinine.
\end{abstract}

Keywords: COVID-19, Kidney disease, Renal recovery

\section{Background}

The ongoing coronavirus disease 2019 (COVID-19) is a worldwide pandemic caused by severe acute respiratory syndrome coronavirus 2 (SARS-CoV-2) $[1,2]$. Up to November 28, 2020 the World Health Organization (WHO) recorded 60,534,526 confirmed cases and 1,426, 101 deaths in 216 countries worldwide [3].

COVID-19 is a respiratory infectious disease that primarily causes pneumonia and severe hypoxemia, but

\footnotetext{
* Correspondence: geshuwang@tjh.tjmu.edu.cn; xugang@tjh.jmu.edu.cn ${ }^{\dagger}$ Nan-Hui Zhang and Yi-Chun Cheng contributed equally to this work. Department of Nephrology, Division of Internal Medicine, Tongji Hospital, Tongji Medical College, Huazhong University of Science and Technology, No.1095 Jiefang Road, Wuhan 430030, Hubei, China
}

the lungs are not the only organ affected. Reports have confirmed that SARS-CoV-2 can invade cells via angiotensin-converting enzyme (ACE2) $[4,5]$ and that ACE2 is highly expressed in the human kidney. Moreover, relevant autopsy data from COVID-19 patients found clusters of coronavirus particles with distinct spikes present in renal tubular epithelial cells [6], suggesting that the kidney may be the target of SARS-COV-2. In addition, available data indicated the high incidence of kidney disease in COVID-19 patients. Previous studies showed that $43.9 \%$ of patients with COVID-19 had proteinuria on admission, while $14.4 \%$ of patients were admitted with elevated blood creatinine [7]. Furthermore, it is reported $65.8 \%$ of patients experienced remission of proteinuria during hospitalization [8]. However, the studies performed

(c) The Author(s). 2021 Open Access This article is licensed under a Creative Commons Attribution 4.0 International License, which permits use, sharing, adaptation, distribution and reproduction in any medium or format, as long as you give appropriate credit to the original author(s) and the source, provide a link to the Creative Commons licence, and indicate if changes were made. The images or other third party material in this article are included in the article's Creative Commons licence, unless indicated otherwise in a credit line to the material. If material is not included in the article's Creative Commons licence and your intended use is not permitted by statutory regulation or exceeds the permitted use, you will need to obtain permission directly from the copyright holder. To view a copy of this licence, visit http://creativecommons.org/licenses/by/4.0/ The Creative Commons Public Domain Dedication waiver (http://creativecommons.org/publicdomain/zero/1.0/) applies to the data made available in this article, unless otherwise stated in a credit line to the data. 
to date have been limited to observations during hospitalization, so the recovery of kidney disease remains unknown in COVID-19 patients who survive after hospitalization.

In the present study, we aimed to describe the incidence and short-term recovery of new-onset kidney disease during hospitalization in COVID-19 patients who discharged alive.

\section{Methods}

\section{Study design and patients}

This was a retrospective and prospective study conducted in Tongji hospital, located in Wuhan, one of the main tertiary teaching hospitals, which was assigned responsibility for the treatments of severe COVID-19 patients by the local government. We included all patients who tested positive by polymerase chain reaction testing of a nasopharyngeal sample for COVID-19, developed new kidney disease during hospitalization, admitted to the Tongji hospital, and were discharged alive from January 28 to February 26, $2020(N=865)$. We excluded the following patients: (1) those aged < 18 years, (2) those who died during hospitalization, (3) those who were dialysis patients, (4) those who were renal allograft recipients, and (5) those with previous chronic kidney disease (CKD), based on careful and repeated history taking. All discharged patients met the uniform discharge criteria of the Chinese clinical guidance for the diagnosis and treatment of COVID-19 pneumonia issued by the National Health Commission (the absence of fever for at least 3 days, substantial improvement in both lungs in chest computed tomography, clinical remission of respiratory symptoms, and two nasal and pharyngeal swab samples negative for SARS-CoV-2 RNA obtained at least $24 \mathrm{~h}$ apart) [9].

All those patients included in the present study were re-contacted after discharge from the hospital to determine their willingness to repeat renal laboratory and urine dipstick tests. Of the 215 patients enrolled in the present study, 143 were available for follow-up (Fig. 1), and 72 patients were lost to follow-up because they declined to participate or did not recheck urine analysis. Therefore, 143 patients finally met the screening criteria and had follow-up data. We compared the characteristics of the 72 patients lost to follow-up and 143 patients with follow-up. It showed no significant difference existing between the two groups (Supplemental Table 1).

Individual-level informed consent was not obtained given the retrospective nature of the analysis of an electronic medical record. The study protocol and waived written informed consent was approved by the Medical Ethics Committee of Tongji Hospital (No.TJ-C20200132). All methods were carried out in accordance with relevant guidelines and regulations.

\section{Data collection and measurement}

The demographic characteristics, clinical symptoms, laboratory data were extracted from electronic medical

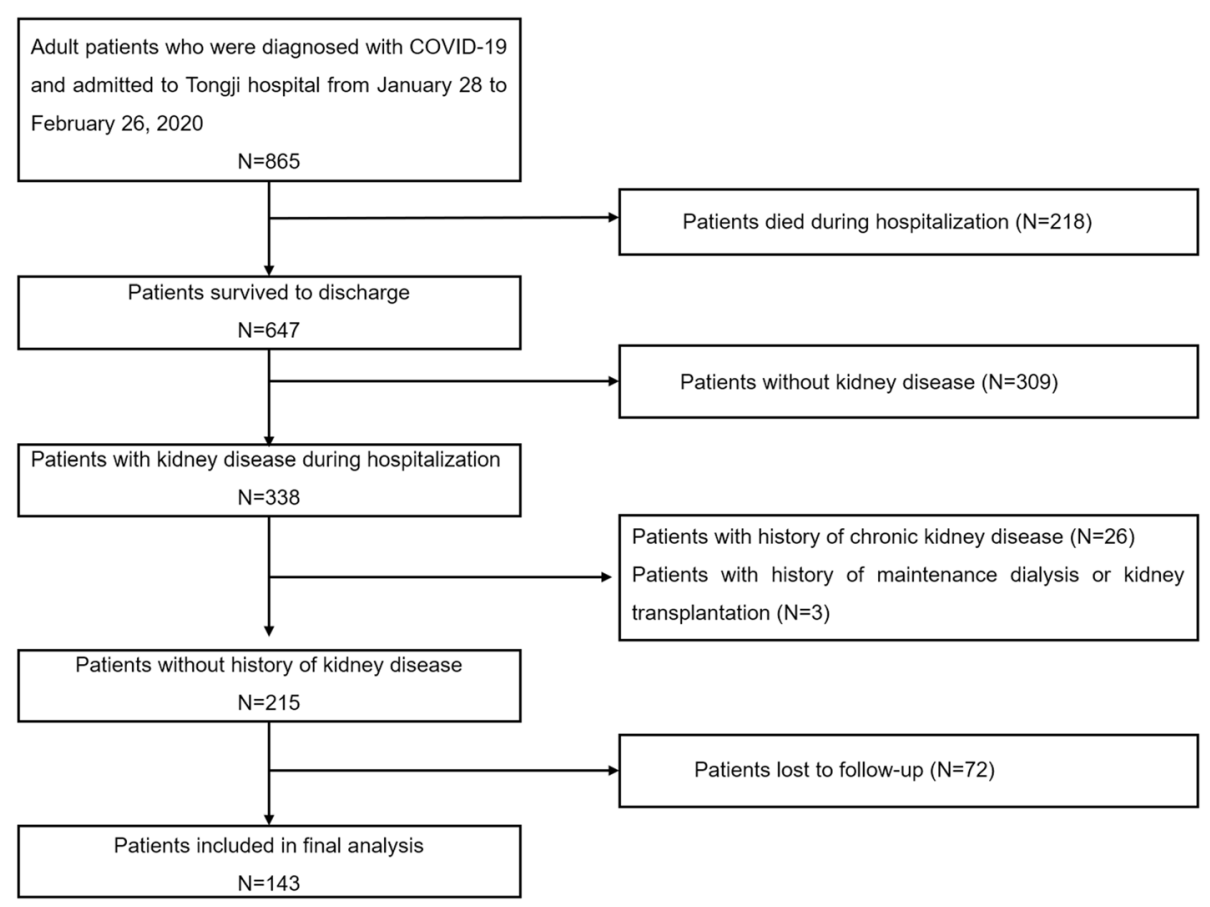

Fig. 1 Flow chart of the selection of eligible subjects 
records. All the comorbidities were reported by patients or family members. Venous blood samples were collected from all participants who attended for follow-up. Serum creatinine, blood urea nitrogen, hemoglobin, leukocyte count, lymphocyte count, platelet count, examination of $\mathrm{D}$-dimer and high-sensitivity $\mathrm{C}$-reactive protein were measured. Urine dipstick test to assess for proteinuria was performed in all patients. The estimated glomerular filtration rate (eGFR) was calculated with Chronic Kidney Disease Epidemiology Collaboration (CKD-EPI) equation [10]. The baseline clinical characteristics and laboratory data were ascertained at the time of admission. The data were reviewed by a trained team of physicians. This has been described in detail in previous studies [11].

The method for detecting SARS-CoV-2 in COVID-19 patients has been described in detail elsewhere [8]. In order to extract SARS-Cov-2 RNA, throat swab samples were collected from patients with possible COVID-19 pneumonia. The respiratory sample RNA isolation kit (Biogerm, Shanghai, China)was used to extract nucleic acids. And SARS-CoV-2 detection kit (Biogerm, Shanghai, China) was used to detect the ORFlab gene (nCovORFlab) and the $\mathrm{N}$ gene (nCoV-NP) according to the manufacturer's instructions, using real-time reverse transcriptionpolymerase chain reaction (RT-PCR). A cycle threshold (Ct) value of 40 or more than was considered that the SARS-CoV-2 RNA was not present and Ct value of 37 to less than 40 required confirmation by retesting.

\section{Definition}

Kidney disease was defined as elevated serum creatine (women: $>84 \mu \mathrm{mol} / \mathrm{L}$; men: $>104 \mu \mathrm{mol} / \mathrm{L}$ ) or positive urine protein on urine dipstick test. Proteinuria was defined as more than trace albumin on urine dipstick tests $(1+, 2+$, or $3+)$, which were collected and detected on the first morning after admission and during the observation period. Patients were included in the recovery group if the serum creatine levels return to normal and urine protein was negative at review, otherwise, patients were included in the non-recovery group.

\section{Statistical analysis}

We performed descriptive statistics including medians and interquartile ranges (IQR) for skewed continuous measures, and proportions for categorical measures. The differences in the categorical variables were evaluated using the chi-square test or Fishers' exact tests, and the continuous variables were compared using the Student's t- test when normally distributed, and the Mann-Whitney test when not. Statistical analyses were performed using $\mathrm{R}$ software, version 3.6.1, with statistical significance set at 2 -sided $P<0.05$.

\section{Results}

\section{Patients' characteristics}

Baseline characteristics, renal function measures, and biomarkers are shown in Table 1 . The mean age was 64 (IQR, 51-70) years, and $59.4 \%$ of patients were men. The most frequent comorbid condition was hypertension in 48 patients (33.6\%) followed by diabetes in 26 patients (18.2\%). Average admission serum creatinine and discharge serum creatinine were $77 \mathrm{mg} / \mathrm{dL}$ and 68 $\mathrm{mg} / \mathrm{dl}$, respectively. The average admission eGFR and discharge eGFR were $88 \mathrm{~mL} / \mathrm{min} / 1.73 \mathrm{~m}^{2}$ and $93 \mathrm{ml} /$ $\min / 1.73 \mathrm{~m}^{2}$. On admission, $83.9 \%$ (120 of 143) patients had a urine dipstick test, and $97.5 \%$ (117 of 120) patients presented with proteinuria $(1+: 82.5 \% ; 2 \sim 3+$ : $15 \%)$. However, only $27.9 \%$ (40 of 143) patients had a urine dipstick test before discharge, and 25\% (10 of 40) patients were still with proteinuria (1+: $90 \%$; 2 3+: $10 \%)$. During hospitalization, $24(16.8 \%)$ patients received mechanical ventilation and $3(2.3 \%)$ patients received extracorporeal membrane oxygenation. And none of the patients had been injected with intravenous contrast dye during their hospitalization.

\section{Characteristic data in the recovery vs. non-recovery group} Of the 143 patients with follow-up data, 91\% (130 of 143) patients recovered from new-onset kidney disease, 9\% (13 of 143) patients didn't during a median followedup of 4 months (Table 2). Comparison of characteristic data between the two groups is shown in Table 2 . Patients in the non-recovery group were significantly older than those in the recovery group. Discharge serum creatinine was significantly higher and discharge eGFR was significantly lower in the non-recovery group than in the recovery group. Greater incidence of discharge proteinuria (66.6\% versus $21.6 \%$ ) was found significantly in the non-recovery group. The systolic blood pressure, comorbidities, admission serum creatinine, admission proteinuria, and leukocyte count were not significantly different between the groups.

Of the 13 patients in the non-recovery group, 3 (23\%) patients reviewed had slightly elevated serum creatinine and negative urine protein (Table 3). Urine dipstick in $10(77 \%)$ patients with proteinuria during hospitalization were still reported as positive after follow-up. It was worth mentioning that in two patients, the creatinine had decreased to normal before discharge and was again elevated upon reexamination.

We also summarized the medication use of both groups during hospitalization (Table 4). Most patients received antiviral therapy $(95.1 \%)$ and antibiotic therapy (87.4\%), and many patients received glucocorticoid therapy (58\%, including at least one dose of dexamethasone in $5 \mathrm{mg}$ or methylprednisolone in $20 \mathrm{mg}$, respectively). The use of antibiotics and glucocorticoids was higher in 
Table 1 Demographic and clinical characteristics

\begin{tabular}{|c|c|c|}
\hline Clinical characteristics & No. & Summary \\
\hline Age, years & 143 & $64(51,70)$ \\
\hline Male patients, No (\%) & 143 & $85(59.4)$ \\
\hline Fever on admission, No (\%) & 143 & $46(32.2)$ \\
\hline Systolic blood pressure, $\mathrm{mmHg}$ & 143 & $128(115,141)$ \\
\hline Diastolic blood pressure, $\mathrm{mmHg}$ & 143 & $80(71,88)$ \\
\hline Smoking, No (\%) & 143 & $9(6.3)$ \\
\hline Any comorbidity, No (\%) & 143 & $69(48.3)$ \\
\hline Chronic lung disease, No (\%) & 143 & $10(7.0)$ \\
\hline Diabetes, No (\%) & 143 & $26(18.2)$ \\
\hline Hypertension, No (\%) & 143 & 48 (33.6) \\
\hline Tumor, No (\%) & 143 & $7(4.9)$ \\
\hline Blood urea nitrogen, mg/dL & 143 & $4.9(3.9,6.3)$ \\
\hline Admission SCr, mg/dL & 143 & $77(61,93)$ \\
\hline Peak SCr, mg/dL & 143 & $84(67,99)$ \\
\hline Discharge SCr, mg/dL & 106 & $68(60,84)$ \\
\hline Admission eGFR, $\mathrm{ml} / \mathrm{min} / 1.73 \mathrm{~m} 2$ & 143 & $88(71,100)$ \\
\hline Peak eGFR, $\mathrm{ml} / \mathrm{min} / 1.73 \mathrm{~m} 2$ & 143 & $81(65,93)$ \\
\hline Discharge eGFR, ml/min/1.73 m2 & 106 & $93(82,103)$ \\
\hline Admission proteinuria & 120 & $117(97.5)$ \\
\hline $1+$ & 120 & $99(82.5)$ \\
\hline $2+\sim 3+$ & 120 & $18(15.0)$ \\
\hline Peak proteinuria & 136 & $130(95.5)$ \\
\hline $1+$ & 136 & 107 (78.6) \\
\hline $2+\sim 3+$ & 136 & $23(16.9)$ \\
\hline discharge proteinuria & 40 & $10(25.0)$ \\
\hline $1+$ & 40 & $9(22.5)$ \\
\hline $2+\sim 3+$ & 40 & $1(2.5)$ \\
\hline Leukocyte count, $\times 10^{9} / \mathrm{L}$ & 143 & $6.2(4.6,8.7)$ \\
\hline Lymphocyte count, $\times 10^{9} / \mathrm{L}$ & 143 & $0.8(0.6,1.0)$ \\
\hline Platelet count, $\times 10^{9} / \mathrm{L}$ & 143 & $197(149,269)$ \\
\hline Hemoglobin, $g / L$ & 143 & $129(121,139)$ \\
\hline D-dimer, mg/L & 135 & $39(19,97)$ \\
\hline hs-CRP, mg/L & 134 & $84(34,134)$ \\
\hline Admission to intensive care unit, No (\%) & 143 & $7(0.05)$ \\
\hline Mechanical ventilation, No (\%) & 143 & $24(16.8)$ \\
\hline Non-invasive, No (\%) & 143 & $22(15.4)$ \\
\hline Invasive, No (\%) & 143 & $6(4.2)$ \\
\hline ECMO, No (\%) & 143 & $3(2.1)$ \\
\hline Hospital length of stay, days & 143 & $27(21,35)$ \\
\hline
\end{tabular}

Values for categorical variables are given as count (percentage); values for continuous variables are given as median (interquartile range). Blood pressure and laboratory data were at the time of admission. SCr serum creatinine; eGFR estimated glomerular filtration rate; $h s-C R P$ high-sensitivity c-reactive protein; ECMO extracorporeal membrane oxygenation the recovery group than in the non-recovery group, although not statistically significant.

\section{Discussion}

In the present study, we included 143 COVID-19 patients with new-onset kidney disease who were discharged alive from the hospital. During a median follow-up of 4 months, we found that 91\% of COVID-19 patients recovered from new-onset kidney disease. Older age and high discharge serum creatinine were associated with non-recovery of kidney disease.

Most COVID-19 patients recovered from new-onset kidney disease 4 months after discharge. The pathophysiology and mechanisms of new-onset kidney disease in patients with COVID-19 have not been fully elucidated. Summarizing the available studies, it was found that the effects of the SARS-CoV-2 virus on the kidneys can be divided into two main aspects, the direct effects of the SARS-CoV-2 virus on the kidneys on the one hand $[6,12]$, and the indirect mechanisms on the kidneys due to the systemic consequences of viral infection and the effects of the virus on other distant organs on the other hand [13]. Furthermore, microscopic examination of autopsies from COVID-19 patients reported microvascular thrombosis, acute tubular necrosis, and lymphocytic infiltration of the kidneys [14-16]. In addition, although not yet fully confirmed, there is evidence that certain genetic traits in COVID-19 patients may increase susceptibility to kidney disease $[17,18]$. Although kidney disease might occur in COVID-19 patients, most patients have a rapid clearance of the SARS-CoV-2 virus from the kidneys. One study examined viral nucleic acid in the urine of COVID-19 patients and found that only 4 out of 58 (6.9\%) patients were positive for urine nucleic acid [19]. Thus SARS$\mathrm{CoV}-2$ virus may not cause long-term kidney damage in most patients with COVID-19. Similar results were found in the patients with COVID-19 after renal transplantation, and 9 of the 10 patients recovered successfully after a long clinical course and viral shedding [20]. A 6-month follow-up study of patients with COVID-19 found $35 \%$ of patients who experienced acute kidney injury during hospitalization had reduced eGFR $(<90 \mathrm{~mL} /$ min per $1.73 \mathrm{~m}^{2}$ ) at follow-up [21]. In our study, 9\% of patients with new-onset kidney disease (with elevated serum creatine or positive urine protein on urine dipstick test) during the COVID-19 hospitalization didn't recover from kidney disease. The inclusion criteria and follow-up endpoints were different between the two studies, which might be the reason for the different results. Long-term kidney recovery data should be evaluated as there was still a subset of COVID-19 patients who did not recover from kidney disease. The timely clearance of the virus, the compensatory loss of renal 
Table 2 Demographic and clinical characteristics of the recovery vs. non-recovery group

\begin{tabular}{|c|c|c|c|c|c|}
\hline \multirow[b]{2}{*}{ Clinical characteristics } & \multicolumn{2}{|c|}{ Recovery group } & \multicolumn{2}{|c|}{ Non-recovery group } & \multirow[t]{2}{*}{$p$ value } \\
\hline & No. & Summary & No. & Summary & \\
\hline Age, years & 130 & $62(50,69)$ & 13 & $72(56,82)$ & 0.034 \\
\hline Male patients, No (\%) & 130 & $77(59.2)$ & 13 & $8(61.5)$ & 0.252 \\
\hline Fever on admission, No (\%) & 130 & $41(31.5)$ & 13 & $5(38.5)$ & 0.756 \\
\hline Systolic blood pressure, $\mathrm{mmHg}$ & 130 & $127(114,141)$ & 13 & $139(121,147)$ & 0.180 \\
\hline Diastolic blood pressure, $\mathrm{mmHg}$ & 130 & $80(72,88)$ & 13 & $80(70,89)$ & 0.974 \\
\hline Smoking, No (\%) & 130 & $7(5.4)$ & 13 & $2(15.4)$ & 0.191 \\
\hline Any comorbidity, No (\%) & 130 & $62(47.7)$ & 13 & $7(53.8)$ & 0.775 \\
\hline Chronic lung disease, No (\%) & 130 & $8(6.2)$ & 13 & $2(15.4)$ & 0.226 \\
\hline Diabetes, No (\%) & 130 & $24(18.5)$ & 13 & $2(15.4)$ & $>0.999$ \\
\hline Hypertension, No (\%) & 130 & $44(33.8)$ & 13 & $4(30.8)$ & $>0.999$ \\
\hline Tumor, No (\%) & 130 & $7(5.4)$ & 13 & $0(0.0)$ & $>0.999$ \\
\hline Blood urea nitrogen, mg/dL & 130 & $5.0(3.9,6.2)$ & 13 & $4.8(3.4,6.6)$ & 0.763 \\
\hline Admission $\mathrm{SCr}, \mathrm{mg} / \mathrm{dL}$ & 130 & $77(62,92)$ & 12 & $83(60,96)$ & 0.577 \\
\hline Peak SCr, mg/dL & 130 & $84(67,99)$ & 13 & $89(65,98)$ & 0.897 \\
\hline Discharge SCr, mg/dL & 96 & $66(60,82)$ & 10 & $83(69,89)$ & 0.015 \\
\hline Admission eGFR, $\mathrm{ml} / \mathrm{min} / 1.73 \mathrm{~m}^{2}$ & 130 & $88(72,100)$ & 12 & $81(59,91)$ & 0.182 \\
\hline Peak eGFR, $\mathrm{ml} / \mathrm{min} / 1.73 \mathrm{~m}^{2}$ & 130 & $81(68,93)$ & 13 & $73(48,92)$ & 0.478 \\
\hline Discharge eGFR, $\mathrm{ml} / \mathrm{min} / 1.73 \mathrm{~m}^{2}$ & 96 & $94(84,103)$ & 10 & $74(66,82)$ & 0.003 \\
\hline Admission proteinuria & 109 & $106(97.2)$ & 11 & $11(100.0)$ & 0.443 \\
\hline $1+$ & 109 & $91(83.5)$ & 11 & $8(72.7)$ & \\
\hline $2+\sim 3+$ & 109 & $15(13.7)$ & 11 & $3(27.3)$ & \\
\hline Peak proteinuria & 124 & $118(95.1)$ & 12 & $12(100.0)$ & 0.341 \\
\hline $1+$ & 124 & 99 (79.8) & 12 & $8(66.7)$ & \\
\hline $2+\sim 3+$ & 124 & $19(15.3)$ & 12 & $4(33.3)$ & \\
\hline discharge proteinuria & 37 & $8(21.6)$ & 3 & $2(66.6)$ & 0.024 \\
\hline $1+$ & 37 & $8(21.6)$ & 3 & $1(33.3)$ & \\
\hline $2+\sim 3+$ & 37 & $0(0.0)$ & 3 & $1(33.3)$ & \\
\hline Leukocyte count, $\times 10^{9} / \mathrm{L}$ & 130 & $6.3(4.6,8.5)$ & 13 & $6.2(5.0,9.2)$ & 0.866 \\
\hline Lymphocyte count, $\times 10^{9} / \mathrm{L}$ & 130 & $0.8(0.6,1.0)$ & 13 & $1.0(0.7,1.2)$ & 0.072 \\
\hline Platelet count, $\times 10^{9} / \mathrm{L}$ & 130 & $195(149,263)$ & 13 & $265(142,347)$ & 0.161 \\
\hline Hemoglobin, g/L & 130 & $129(121,139)$ & 13 & $125(114,128)$ & 0.114 \\
\hline D-dimer, mg/L & 123 & $41(19,69)$ & 12 & $31(20,40)$ & 0.120 \\
\hline hs-CRP, mg/L & 123 & $88(38,135)$ & 11 & $64(13,107)$ & 0.219 \\
\hline Admission to intensive care unit, No (\%) & 130 & $7(0.1)$ & 13 & $0(0.0)$ & $>0.999$ \\
\hline Mechanical ventilation, No (\%) & 130 & $24(18.5)$ & 13 & $0(0.0)$ & 0.126 \\
\hline Non-invasive, No (\%) & 130 & $22(16.9)$ & 13 & $0(0.0)$ & 0.219 \\
\hline Invasive, No (\%) & 130 & $6(4.6)$ & 13 & $0(0.0)$ & $>0.999$ \\
\hline ECMO, No (\%) & 130 & $3(2.3)$ & 13 & $0(0.0)$ & $>0.999$ \\
\hline Hospital length of stay, days & 130 & $28(21,36)$ & 13 & $21(17,26)$ & $>0.999$ \\
\hline
\end{tabular}

Values for categorical variables are given as count (percentage); values for continuous variables are given as median (interquartile range). Blood pressure and laboratory data were at the time of admission. SCr serum creatinine; EGFR estimated glomerular filtration rate; $h s$-CRP high-sensitivity c-reactive protein; ECMO extracorporeal membrane oxygenation 


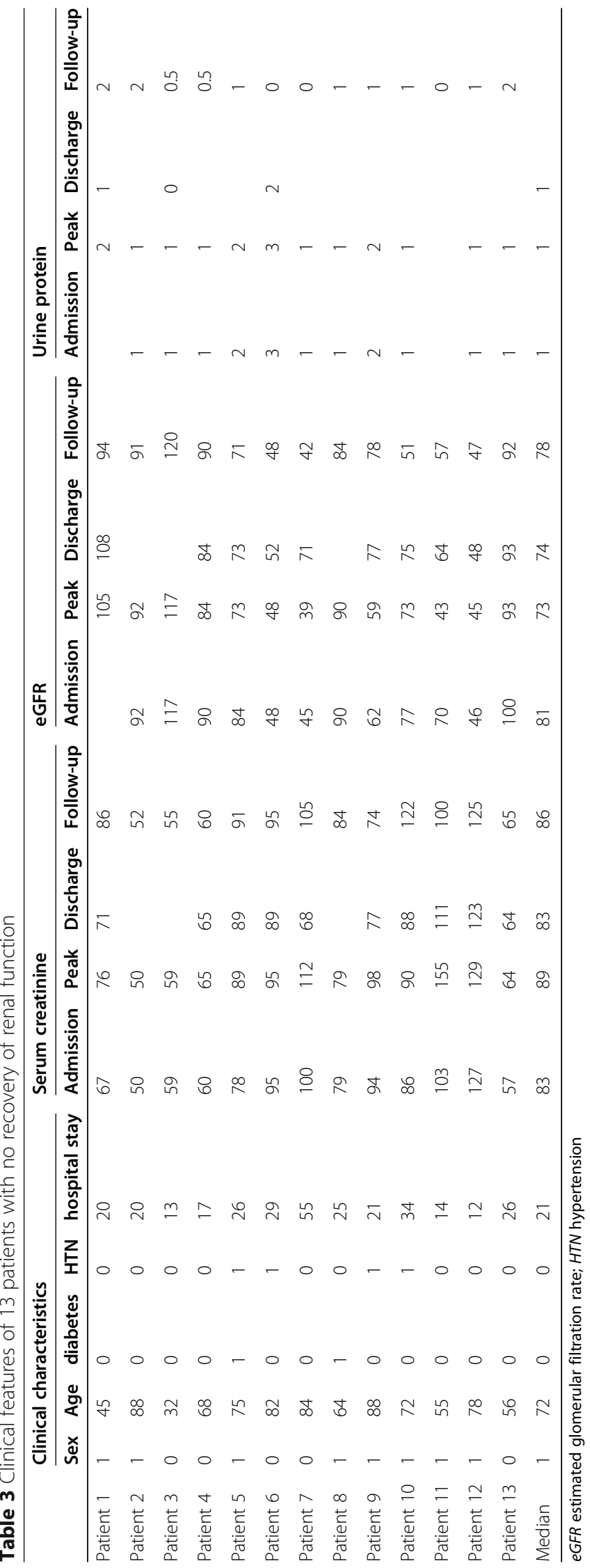


Table 4 Medications used during hospitalization

\begin{tabular}{lllll}
\hline & $\begin{array}{l}\text { All patients } \\
(\mathbf{N = 1 4 3 )}\end{array}$ & $\begin{array}{l}\text { Recovery group } \\
(\mathbf{N = 1 3 0 )}\end{array}$ & $\begin{array}{l}\text { Non-recovery group } \\
(\mathbf{N = 1 3 )}\end{array}$ \\
\hline RAAS inhibitors, No (\%) & $16(11.2)$ & $14(10.8)$ & $2(15.4)$ & $10(76.9)$ \\
Antibiotics, No (\%) & $125(87.4)$ & $115(88.5)$ & $13(100.0)$ & 0.641 \\
Antivirus, No (\%) & $136(95.1)$ & $123(94.6)$ & $2(15.4)$ & 0.212 \\
Antidiabetic, No (\%) & $37(25.9)$ & $35(26.9)$ & $0(0.0)$ & 0.915 \\
Diuretic, No (\%) & $18(12.6)$ & $18(13.8)$ & $6(46.2)$ & 0.372 \\
Glucocorticoid, No (\%) & $83(58.0)$ & $77(59.2)$ & & 0.390 \\
\hline
\end{tabular}

Values for categorical variables are given as count (percentage); RAAS renin-angiotensin-aldosterone system

function after injury, and the absence of subsequent renal fibrosis might be key to the recovery mechanism. Further research is needed to better and more deeply understand the underlying mechanisms by which kidney disease occurs in COVID-19 patients and the mechanisms of recovery [22].

Older COVID-19 patients had a harder time recovering from new-onset kidney disease during hospitalization. Available results suggested that older people are more susceptible to COVID-19 infection [23] and that the older the age, the higher the mortality rate of COVID-19 infection $[24,25]$. Our results showed that advanced age is a risk factor for non-recovery of kidney disease in patients with COVID-19. Indeed, the available studies suggested that the immune system appears to maintain a mild inflammatory state with advancing age and that the activation of SARSCoV-2 invasion exaggerates the magnitude of the immune response [26]. In addition, aging is closely associated with a decline in kidney function [27]. Renal aging is characterized by a progressive increase in nephrosclerosis, loss of glomerular function, and consequently a decline in overall renal function [28]. Although to some extent, the reduction in the cortical volume of the kidney caused by nephrosclerosis is compensated by nephron hypertrophy of the remaining kidney in the medulla. However, when the patient is older than 50 years, this compensation is inadequate, and the total renal volume begins to decline [29]. In addition, elderly patients' ability to recover from kidney damage is diminished [30]. To date, however, no study has shown that the kidneys of older people are more susceptible to, or more difficult to recover from, viral infections. Studies of potential mechanisms, identifying those factors associated with non-recovery of kidney disease and improving prognosis of kidney disease in elderly COVID-19 patients are urgently needed. Available short-term evidence suggests that older patients are more difficult to recover from kidney disease. Besides, available evidence suggests that older age is associated with worse outcomes in patients with COVID-19 [31, 32]. Therefore, renal function and proteinuria should be closely monitored and followed in elderly COVID-19 patients with new-onset kidney disease to prevent progression in clinical practice.
A high creatinine value at discharge and a positive urine dipstick test result were associated with nonrecovery of kidney disease. During the hospitalization of COIVD-19 patients with new-onset kidney disease, it is necessary to closely monitor the laboratory data of renal function and urine protein dipstick test, especially before discharge. Elevated serum creatinine values and urine dipstick test positive results at discharge may be superior to help identify patients at highest risk for kidney disease and difficulty in recovery. The present study suggests that reexamination of serum creatinine and urine dipstick test before discharge may have a role in renal outcome assessment after kidney disease during hospitalization for COVID-19. Thus, to improve kidney recovery in COVID-19 patients, frequent monitoring of serum creatinine should be encouraged, especially before patients are discharged from the hospital. Regrettably, appropriate preventive surveillance strategies for kidney disease have not been widely implemented in most COVID-19 wards. Interestingly, we found that two COVID patients with new-onset kidney disease had their creatinine returned to the normal range before discharge. However, 4 months after they were discharged from the hospital, the laboratory results showed that the creatinine increased again. Additional studies are needed to address these issues. For COVID-19 patients with new-onset kidney disease during hospitalization, the reexamination of serum creatinine was recommended even if patients had normal discharged serum creatinine.

There are several limitations to this study. First, this study included a limited number of patients, all from one hospital. Second, because of the strain on medical resources caused by the sudden onset of the COVID-19 epidemic, we could not obtain comprehensive laboratory data, such as $24 \mathrm{~h}$ urinary protein quantification. Third, lack of data on medication exposure (e.g. non-steroid anti-inflammatory drugs) that may cause kidney injury during the follow-up period. Fourth, approximately $33 \%$ of the patients were lost to follow-up and were older than the follow-up patients. Our results may overestimate the recovery rate. 


\section{Conclusion}

Our study found that most of the new-onset kidney diseases during hospitalization of COVID-19 patients recovered 4 months after discharge. We recommend that COVID-19 patients with new-onset kidney disease be followed after discharge to evaluate kidney recovery, especially elderly patients or patients with high discharge creatinine. Larger prospective studies are needed to confirm the effectiveness of these measures.

\section{Supplementary Information}

The online version contains supplementary material available at https://doi. org/10.1186/s12879-021-06105-8

Additional file 1: Table E1. Baseline characteristics of Patients with and without follow-up data.

\section{Acknowledgements}

The authors greatly appreciate all the hospital staff for their efforts in recruiting and treating patients and thank all patients involved in this study.

\section{Authors' contributions}

GX and SG designed the study. NZ, YC, RL, and CZ collected the data and prepared the figures and Tables. NZ, YC, and RL contributed analytical tools. NZ and YC wrote the paper.SG and GX conceived the project and supervised and coordinated all the work. The author(s) read and approved the final manuscript.

\section{Funding}

This work was financially supported by the International (Regional) Cooperation and Exchange Projects (NSFC-DFG Grant No. 81761138041); National Natural Science Foundation of China (Grant Nos. 81570667); Major Research Plan of the National Natural Science Foundation of China (Grant No. 91742204); The National Key R\&D Program of China (Grant Nos. 2018YF(1314003-1).

\section{Availability of data and materials}

The datasets used in this study are available from the corresponding author on reasonable request.

\section{Declarations}

\section{Ethics approval and consent to participate}

This study was approved by the Medical Ethics Committee of Tongji Hospital (No. TJ-C20200132) and a waiver of informed consent was granted. Data collected from the study participants was kept anonymous and treated as confidential at all times.

\section{Consent for publication}

Not applicable.

\section{Competing interests}

All authors declare no conflict of interest.

Received: 26 January 2021 Accepted: 20 April 2021

Published online: 29 April 2021

\section{References}

1. Zhu N, Zhang D, Wang W, Li X, Yang B, Song J, et al. A novel coronavirus from patients with pneumonia in China, 2019. N Engl J Med. 2020;382(8): 727-33. https://doi.org/10.1056/NEJMoa2001017.

2. Z Zhou P, Yang X-L, Wang X-G, Hu B, Zhang L, Zhang W, et al. A pneumonia outbreak associated with a new coronavirus of probable bat origin. Nature. 2020;579(7798):270-3. https://doi.org/10.1038/s41586-020-2012-7.

3. World Health Organisation [Internet]. 2020 Coronavirus disease (COVID-19) situation reports. https://wwwwhoint/emergencies/diseases/novel-corona virus-2019/situation-reports/ Assessed 28 Nov 2020.
4. Ye M, Wysocki J, William J, Soler MJ, Cokic I, Batlle D. Glomerular localization and expression of angiotensin-converting enzyme 2 and angiotensinconverting enzyme: implications for albuminuria in diabetes. J Am Soc Nephrol. 2006;17(11):3067-75. https://doi.org/10.1681/ASN.2006050423.

5. Donoghue M, Hsieh F, Baronas E, Godbout K, Gosselin M, Stagliano N, et al. A novel angiotensin-converting enzyme-related carboxypeptidase (ACE2) converts angiotensin I to angiotensin 1-9. Circ Res. 2000;87(5):E1-9. https:// doi.org/10.1161/01.res.87.5.e1.

6. Su H, Yang M, Wan C, Yi L-X, Tang F, Zhu H-Y, et al. Renal histopathological analysis of 26 postmortem findings of patients with COVID-19 in China. Kidney Int. 2020;98(1):219-27. https://doi.org/10.1016/j.kint.2020.04.003.

7. Cheng Y, Luo R, Wang K, Zhang M, Wang Z, Dong L, et al. Kidney disease is associated with in-hospital death of patients with COVID-19. Kidney Int. 2020;97(5):829-38. https://doi.org/10.1016/j.kint.2020.03.005.

8. Pei G, Zhang Z, Peng J, Liu L, Zhang C, Yu C, et al. Renal involvement and early prognosis in patients with COVID-19 pneumonia. J Am Soc Nephrol. 2020;31(6):1157-65. https://doi.org/10.1681/ASN.2020030276.

9. China National Health Commission Chinese clinical guidance for COVID-19 pneumonia diagnosis and treatment. http://kjfy.meetingchina.org/msite/ news/show/cn/3337.html. Accessed 20 June 2020.

10. Levey AS, Stevens LA, Schmid CH, Zhang YL, Castro AF 3rd, Feldman HI, et al. A new equation to estimate glomerular filtration rate. Ann Intern Med. 2009; 150(9):604-12. https://doi.org/10.7326/0003-4819-150-9-200905050-00006.

11. Cheng Y, Luo R, Wang X, Wang K, Zhang N, Zhang M, et al. The incidence, risk factors, and prognosis of acute kidney injury in adult patients with coronavirus disease 2019. Clin J Am Soc Nephrol. 2020;15(10):1394-402. https://doi.org/10.2215/CJN.04650420.

12. Farkash EA, Wilson AM, Jentzen JM. Ultrastructural evidence for direct renal infection with SARS-CoV-2. J Am Soc Nephrol. 2020;31(8):1683-7. https://doi. org/10.1681/ASN.2020040432.

13. Cuadrado-Payán E, Montagud-Marrahi E, Torres-Elorza M, Bodro M, Blasco M, Poch E, et al. SARS-CoV-2 and influenza virus co-infection. Lancet. 2020; 395(10236):e84. https://doi.org/10.1016/S0140-6736(20)31052-7.

14. Santoriello D, Khairallah P, Bomback AS, Xu K, Kudose S, Batal I, et al. Postmortem kidney pathology findings in patients with COVID-19. J Am Soc Nephrol. 2020;31(9):2158-67. https://doi.org/10.1681/ASN.2020050744.

15. Batlle D, Soler MJ, Sparks MA, Hiremath S, South AM, Welling PA, et al. Acute kidney injury in COVID-19: emerging evidence of a distinct pathophysiology. J Am Soc Nephrol. 2020;31(7):1380-3. https://doi.org/10.1681/ASN.2020040419.

16. Sharma P, Uppal NN, Wanchoo R, Shah HH, Yang Y, Parikh R, et al. COVID19-associated kidney injury: a case series of kidney biopsy findings. J Am Soc Nephrol. 2020;31(9):1948-58. https://doi.org/10.1681/ASN.2020050699.

17. Wu H, Larsen CP, Hernandez-Arroyo CF, Mohamed MMB, Caza T. Sharshir md, Chughtai a, Xie L, Gimenez JM, Sandow TA et al: AKI and collapsing Glomerulopathy associated with COVID-19 and high-risk genotype. J Am Soc Nephrol. 2020;31(8):1688-95. https://doi.org/10.1681/ASN.2020050558.

18. Velez JCQ, Caza T, Larsen CP. COVAN is the new HIVAN: the re-emergence of collapsing glomerulopathy with COVID-19. Nat Rev Nephrol. 2020;16(10): 565-7. https://doi.org/10.1038/s41581-020-0332-3.

19. Ling Y, Xu S-B, Lin Y-X, Tian D, Zhu Z-Q, Dai F-H, et al. Persistence and clearance of viral RNA in 2019 novel coronavirus disease rehabilitation patients. Chin Med J. 2020;133(9):1039-43. https://doi.org/10.1097/CM9. 0000000000000774.

20. Zhu L, Gong N, Liu B, Lu X, Chen D, Chen S, et al. Coronavirus disease 2019 pneumonia in immunosuppressed renal transplant recipients: a summary of 10 confirmed cases in Wuhan, China. Eur Urol. 2020;77(6):748-54. https:// doi.org/10.1016/j.eururo.2020.03.039.

21. Huang C, Huang L, Wang Y, Li X, Ren L, Gu X, et al. 6-month consequences of COVID-19 in patients discharged from hospital: a cohort study. Lancet. 2021;397(10270):220-32. https://doi.org/10.1016/S0140-6736(20)32656-8.

22. Nadim MK, Forni LG, Mehta RL, Connor MJ, Liu KD, Ostermann M, et al. COVID-19-associated acute kidney injury: consensus report of the 25th acute disease quality initiative (ADQI) workgroup. Nat Rev Nephrol. 2020; 16(12):747-64. https://doi.org/10.1038/s41581-020-00356-5.

23. Verity R, Okell LC, Dorigatti I, Winskill P, Whittaker C, Imai N, et al. Estimates of the severity of coronavirus disease 2019: a model-based analysis. Lancet Infect Dis. 2020;20(6):669-77. https://doi.org/10.1016/S1473-3099(20)30243-7.

24. Ma Y, Hou L, Yang $X$, Huang Z, Yang $X$, Zhao N, et al. The association between frailty and severe disease among COVID-19 patients aged over 60 years in China: a prospective cohort study. BMC Med. 2020;18(1):274. https://doi.org/10.1186/s12916-020-01761-0. 
25. Santesmasses D, Castro JP, Zenin AA, Shindyapina AV, Gerashchenko MV, Zhang B, et al. COVID-19 is an emergent disease of aging. Aging Cell. 2020; 19(10):e13230. https://doi.org/10.1111/acel.13230.

26. Cao X. COVID-19: immunopathology and its implications for therapy. Nat Rev Immunol. 2020;20(5):269-70. https://doi.org/10.1038/s41577-020-0308-3.

27. Zhou XJ, Rakheja D, Yu X, Saxena R, Vaziri ND, Silva FG. The aging kidney. Kidney Int. 2008;74(6):710-20. https://doi.org/10.1038/ki.2008.319.

28. Denic A, Glassock RJ, Rule AD. Structural and functional changes with the aging kidney. Adv Chronic Kidney Dis. 2016;23(1):19-28. https://doi.org/10.1 053/j.ackd.2015.08.004.

29. Gekle M. Kidney and aging - a narrative review. Exp Gerontol. 2016;87.

30. Chao C-T, Tsai H-B, Lin Y-F, Ko W-J. Acute kidney injury in the elderly: only the tip of the iceberg. J Clin Gerontol Geriatr. 2014;5(1):7-12. https://doi. org/10.1016/j.jcgg.2013.04.002.

31. Heras E, Garibaldi P, Boix M, Valero O, Castillo J, Curbelo Y, et al. COVID-19 mortality risk factors in older people in a long-term care center. Eur Geriatr Med. 2020:1-7.

32. Higham A, Mathioudakis A, Vestbo J, Singh D. COVID-19 and COPD: a narrative review of the basic science and clinical outcomes. Eur Respir Rev. 2020;29:158.

\section{Publisher's Note}

Springer Nature remains neutral with regard to jurisdictional claims in published maps and institutional affiliations.

Ready to submit your research? Choose BMC and benefit from:

- fast, convenient online submission

- thorough peer review by experienced researchers in your field

- rapid publication on acceptance

- support for research data, including large and complex data types

- gold Open Access which fosters wider collaboration and increased citations

- maximum visibility for your research: over $100 \mathrm{M}$ website views per year

At BMC, research is always in progress.

Learn more biomedcentral.com/submissions 